\title{
Clinical and radiological outcome following pneumothorax after endoscopic lung volume reduction with valves
}

This article was published in the following Dove Press journal:

International Journal of COPD

7 December 2016

Number of times this article has been viewed

\author{
D Gompelmann ${ }^{1,2}$ \\ N Benjamin' \\ K Kontogianni' \\ FJF Herth ${ }^{1,2}$ \\ CP Heussel ${ }^{2-4}$ \\ H Hoffmann ${ }^{2,5}$ \\ R Eberhardt ${ }^{1,2}$
}

'Pneumology and Critical Care Medicine, Thoraxklinik at University of Heidelberg, ${ }^{2}$ German Center for Lung Research, ${ }^{3}$ Diagnostic and Interventional Radiology, Thoraxklinik at University of Heidelberg,

${ }^{4}$ Diagnostic and Interventional Radiology, University Hospital Heidelberg, ${ }^{5}$ Thoracic Surgery, Thoraxklinik at University of Heidelberg, Heidelberg, Germany
Correspondence: D Gompelmann Pneumology and Critical Care Medicine, Thoraxklinik at University of Heidelberg, Röntgenstrasse I, 69126 Heidelberg, Germany Tel +4962213968087 $\mathrm{Fax}+496221396 \quad 1202$ Email daniela.gompelmann@med. uni-heidelberg.de
Introduction: Valve implantation has evolved as a therapy for patients with advanced emphysema. Although it is a minimally invasive treatment, it is associated with complications, the most common being pneumothorax. Pneumothorax occurs due to the rapid target lobe volume reduction and may be a predictor of clinical benefit despite this complication.

Objective: The objective of this study was to conduct an exploratory data analysis of patients who developed a pneumothorax following endoscopic valve therapy for emphysema.

Materials and methods: This study performed a retrospective evaluation of pneumothorax management and the impact of pneumothorax on clinical outcomes in 70 patients following valve therapy in 381 consecutive patients.

Results: Pneumothorax rate following valve therapy was $18 \%$. Pneumothorax management consisted of chest tube insertion, valve removal, and surgical intervention in 87\% (61/70), 44\% (31/70), and 19\% (13/70) of the patients, respectively. Despite pneumothorax, patients experienced modest but significant improvements in lung function parameters (forced expiratory volume in 1 second: $55 \pm 148 \mathrm{~mL}$, residual volume: $-390 \pm 964 \mathrm{~mL}$, total lung capacity: $-348 \pm 876$; all $P<0.05$ ). Persistent lobar atelectasis 3 months after recovering from pneumothorax, which was associated with relevant clinical improvement, was observed in only $21 \%(15 / 70)$ of the patients.

Conclusion: Pneumothorax is a frequent severe complication following valve therapy that requires further intervention. Nevertheless, the pneumothorax does not impair the clinical status in the majority of patients. Patients with lobar atelectasis benefit after recovering from pneumothorax in terms of lung function parameters.

Keywords: COPD, emphysema, endoscopic valve therapy, pneumothorax

\section{Introduction}

Since 2003, valve implantation has evolved as a new therapy in patients with advanced emphysema. ${ }^{1,2}$ Thereby, one-way valves that allow air to exit during expiration but block inspired air are implanted into the bronchi of the most emphysematous lobe, thus leading to lobar volume reduction. By this mechanism, valve therapy minimizes hyperinflation, which impairs functional capacity and influences mortality in patients with COPD. ${ }^{3}$

The first randomized controlled trials (RCTs) related to valve therapy, known as VENT and Euro-VENT, demonstrated that particularly patients with complete interlobar fissure on high-resolution computed tomography (CT) and thus low interlobar collateral ventilation $(\mathrm{CV})$ who had received a complete occlusion of the target lobe experienced relevant clinical improvement. ${ }^{4,5}$ Based on this knowledge, only patients who fulfill these prerequisites were enrolled in the following recently published RCT. ${ }^{6}$ 
In the STELVIO trial, 25 patients with absent CV were treated with valves and compared with 33 patients of a control group. ${ }^{6}$ Efficacy data demonstrated a statistically significant and clinically relevant outcome in the valve group. The adjusted patient selection in comparison to the VENT influenced the spectrum of adverse events and led to a higher rate of complications of which pneumothorax was the most common. In VENT, pneumothorax rate was reported at $4.2 \%$, whereas pneumothorax rate increased up to $18 \%$ in STELVIO. In further trials, the authors reported even higher pneumothorax rates of $20 \%-25 \%{ }^{7,8}$ It is likely that a parenchymal rupture of the ipsilateral, untreated lobe due to a rapid expansion because of the volume reduction of the treated lobe is the reason for the occurrence of pneumothorax. Although pneumothorax is a severe complication that may present a life-threatening situation and is associated with prolonged hospitalization, immobilization, and further invasive interventions, it does not appear to have a negative impact on patients' outcome. One retrospective trial evaluated the clinical outcome of 25 patients who developed a pneumothorax following valve placement. ${ }^{9}$ Despite the pneumothorax, patients achieved a substantial lobar volume reduction of $65 \% \pm 36 \%$, which was associated in most cases with excellent clinical outcomes. However, as the number of patients is very low in this study population, it is not possible to make a general statement on the impact of pneumothorax on clinical outcomes. Therefore, a further retrospective analysis evaluating the impact of pneumothorax on outcome measures following valve placement was performed in order to better assess the influence of this common complication.

\section{Materials and methods}

The database was queried for patients with severe emphysema, who were treated by endoscopic valve therapy between January 2009 and December 2013 at the Thoraxklinik at the University of Heidelberg. In this analysis, clinical outcome measures and radiological outcomes of patients who developed pneumothorax during a follow-up of up to 1 year following valve placement were evaluated. The protocol of this trial was approved by the local ethics committee of the University of Heidelberg (S-609/2012). The majority of the patients were treated within various prospective trials after written informed consent was obtained. As the data in this current analysis were retrospectively analyzed no further patient consent was required.

\section{Subject enrollment}

All patients with severe emphysema who experienced a pneumothorax following the placement of endobronchial valves (Pulmonx, Neuchatel, Switzerland) and/or intrabronchial valves (Olympus Corporation, Tokyo, Japan) into the most emphysematous lobe were enrolled in the analysis. All patients treated with valves suffered from severe emphysema, which had been confirmed in baseline lung function tests demonstrating a significant forced expiratory volume in 1 second $\left(\mathrm{FEV}_{1}\right)$ reduction and severe hyperinflation. Furthermore, each patient had undergone multi-detector CT, including software analysis (yet another CT analyzer, YACTA) and perfusion scan in order to identify the most emphysematous lobe as the target lobe.

\section{Pneumothorax assessment}

All pneumothoraces occurring during 1 year following valve placement were recorded. The prevalence, onset, duration, and management of pneumothorax following valve treatment were assessed. In the case of pneumothorax, the subsequent procedure (chest tube insertion, valve removal, video-assisted thoracoscopy or thoracotomy) was dependent on the extent of the pneumothorax and/or clinical symptoms. The treatment algorithm for a post-interventional pneumothorax was derived from the expert statement published in 2014 . $^{10}$ In brief, the first step in symptomatic or large pneumothorax is the immediate insertion of a chest tube. In case of an ongoing air leak for $>7$ days or in case of a lack of full lung re-expansion, the removal of one valve should be considered in order to inflate the target lobe again and thus re-establish pleural contact. If the air leak continues or no re-expansion is achieved, all valves should be removed. If these interventions remain unsuccessful, pleurodesis or surgical intervention needs to be considered. In summary, the pneumothorax management can vary depending on the clinical signs, the amount of air leak, and the existence of soft tissue emphysema.

\section{Assessment of clinical data}

The data were collected by reviewing medical reports and radiological imaging. Lung function parameters (vital capacity $[\mathrm{VC}], \mathrm{FEV}_{1}$, residual volume [RV], total lung capacity [TLC]), exercise test (6-minute walk test [6-MWT]), and dyspnea score (modified Medical Research Council [mMRC]) were collected from each patient prior to valve placement and 3 months after recovering from pneumothorax. For each patient, all chest X-rays and CT scans taken following the valve therapy were reviewed. The patients were divided into two subgroups depending on whether a complete lobar atelectasis could be observed. The patients with complete lobar atelectasis as the maximum radiological result following valve placement belonged to the atelectasis group, 
whereas the other subgroup consisted of patients with partial atelectasis, dystelectasis or no change in volume.

\section{Statistical analysis}

Statistical analysis was performed using SPSS Statistics (IBM SPSS Statistics for Windows, Version 22.0; IBM Corporation, Armonk, NY, USA). Data are presented as mean \pm standard deviation, minimum and maximum, or $\mathrm{n}$ and $\%$ for frequency data. Changes from baseline to follow-up in lung function, exercise capacity, and $\mathrm{mMRC}$ were expressed by descriptive statistics (mean, range, standard deviation). Statistical comparison for the pre-interventional baseline examinations versus follow-up examinations was made using the paired two-sided $t$-test. Missing data were imputed by an additional multivariate imputation on the basis of the patients' baseline values. $P$-values $<0.05$ was considered as statistically significant.

\section{Results}

From January 2009 to December 2013, 381 patients with severe emphysema received endoscopic valve therapy. The mean age was 64 years (range: $41-81$ years), and $52 \%$ of them were males. The mean $\mathrm{FEV}_{1}$ was $0.8 \mathrm{~L}$ and the mean RV was $262 \% \pm 21 \%$ predicted (Table 1 ). The left lower lobe was the most common target lobe (Table 2).

Overall, 18\% (70/381) of the patients developed a pneumothorax as a complication following valve implantation (Figure 1). In 51 out of 65 patients (79\%), pneumothorax occurred within the first 3 days following intervention (median time to pneumothorax was 1 day [range: $0-125$ days]). In the remaining five patients, pneumothorax onset and duration were unknown, as these patients developed pneumothorax outside the hospital and were referred to other centers.

In $13 \%(9 / 70)$ of the patients, pneumothorax resolved under careful observation. In $87 \%(61 / 70)$ of the patients, chest tube insertion was necessary. In $51 \%(31 / 61)$ of these

Table I Baseline characteristics of all patients treated by valves

\begin{tabular}{lllll}
\hline $\begin{array}{l}\text { Baseline clinical } \\
\text { measures }\end{array}$ & $\mathbf{n}$ & Mean \pm SD & Min & Max \\
\hline VC (L) & $38 I$ & $2.4 \pm 0.65$ & 0.6 & 4.9 \\
VC (\% predicted) & 378 & $69.2 \pm 12.37$ & 21 & 118.7 \\
FEV, (L) $_{\text {FEV } \text { (\% predicted) }}$ & $38 \mathrm{I}$ & $0.8 \pm 0$ & 0.3 & 2.1 \\
RV (L) & 380 & $30.1 \pm 0.92$ & 11.7 & 74.2 \\
RV (\% predicted) & 379 & $5.7 \pm 0.35$ & 3.1 & 9.2 \\
TLC (L) & 378 & $261.7 \pm 21.4$ & 143.5 & 523 \\
TLC (\% predicted) & 380 & $139.2 \pm 12.7$ & 89.9 & 232 \\
6-MWT (m) & 343 & $272.3 \pm 110.3$ & 30 & 490 \\
mMRC (points) & 309 & $2.8 \pm 1.4$ & 0 & 4 \\
\hline
\end{tabular}

Abbreviations: SD, standard deviation; VC, vital capacity; FEV , forced expiratory volume in I second; RV, residual volume; TLC, total lung capacity; 6-MWT, 6-minute walk test; mMRC, modified Medical Research Council; Min, minimum; Max, maximum. patients, chest drain insertion did not lead to the resolution of pneumothorax, so valve removal was required. Despite chest tube drainage and valve removal, a persistent fistula was observed in $45 \%$ (14/31) of the patients, necessitating a talc slurry in one patient and additional surgical interventions in 13 patients (video-assisted thoracoscopy 77\% [10/13], thoracotomy $15 \%$ [2/13] or both $8 \%$ [1/13]). During the first 3 months after valve explantation, 5 of the 31 patients in whom valve removal had been performed underwent reimplantation of the valve to achieve a lobar occlusion again.

Three months after recovering from pneumothorax, the patients experienced a modest improvement in lung function parameters, 6-MWT and mMRC (Table 3).

In $60 \%$ of the patients with pneumothorax $(42 / 70)$, no complete lobar atelectasis was observed at any time. However, these patients did show a statistically significant improvement in RV (\%) and TLC (\%; Table 4). Thirty-two percent $(11 / 34)$ of these patients met the efficacy threshold of $>100 \mathrm{~mL}$ improvement in $\mathrm{FEV}_{1}$, and $54 \%$ (14/26) of the patients experienced a 6-MWT improvement of $>26 \pm 2 \mathrm{~m} .{ }^{11,12}$ Fifteen percent (5/34) of the patients experienced an $\mathrm{FEV}_{1}$ worsening of $>100 \mathrm{~mL}$ and $31 \%$ (8/26) developed a decrease in the 6-MWT of $>26 \pm 2 \mathrm{~m}$ (Figure 2A and B).

In $40 \%(28 / 70)$ of all pneumothorax patients, a lobar atelectasis was observed radiologically. In $64 \%$ (16/28) of the patients, atelectasis was confirmed after recovering from pneumothorax, and in 36\% (12/28) of the patients, atelectasis was confirmed prior/during pneumothorax. Three months following pneumothorax, valve therapy was associated with significant improvement in all lung function parameters except VC (Table 5). Forty-two percent (8/19) of the patients met the efficacy threshold of $>100 \mathrm{~mL}$ improvement in $\mathrm{FEV}_{1}$, and $56 \%(9 / 16)$ of the patients experienced a 6-MWT improvement of $>26 \pm 2 \mathrm{~m}$. In $5 \%$ (1/19) of the patients, an $\mathrm{FEV}_{1}$ worsening of $>100 \mathrm{~mL}$ and in $25 \%(4 / 16)$ of the patients, a decrease in the 6-MWT of $>26 \pm 2 \mathrm{~m}$ could be observed (Figure $2 \mathrm{~A}$ and B). In 54\% (15/28) of the patients, atelectasis was still confirmed 3 months after recovering from pneumothorax. Regarding only these 15 patients with persistent lobar atelectasis 3 months after recovering from pneumothorax, great improvements were observed ( $\triangle \mathrm{VC}: 299 \pm 463 \mathrm{~mL}, \Delta \mathrm{VC}: 11.7 \% \pm 15 \%$ predicted, $\Delta \mathrm{FEV}_{1}: 122 \pm 143 \mathrm{~mL}, \Delta \mathrm{FEV}_{1}: 5.1 \% \pm 5.4 \%$ predicted, $\Delta \mathrm{RV}:-995 \pm 744 \mathrm{~mL}, \Delta \mathrm{RV}:-43.8 \% \pm 33.9 \%$ predicted, $\Delta$ TLC: $-653 \pm 573 \mathrm{~mL}, \Delta \mathrm{TLC}:-10.7 \% \pm 9.1 \%$ predicted, $\Delta 6$-MWT: $22.8 \mathrm{~m} \pm 56.8 \mathrm{~m}, \Delta \mathrm{mMRC}:-0.8 \pm 1.6$ points).

\section{Discussion}

Efficacy of endoscopic valve therapy in patients with severe emphysema and low $\mathrm{CV}$ was demonstrated in various different 
Table 2 Distribution of treated target lobe

\begin{tabular}{|c|c|c|c|c|}
\hline \multirow[t]{2}{*}{ Target lung area } & \multicolumn{2}{|c|}{$\begin{array}{l}\text { Target lobe of valve } \\
\text { placement }(n=38 I)\end{array}$} & \multicolumn{2}{|c|}{$\begin{array}{l}\text { Advent of pneumothorax related to } \\
\text { target lobe }(n=70)\end{array}$} \\
\hline & $\mathbf{n}$ & $\begin{array}{l}\% \text { (in relation to total } \\
\text { number treated) }\end{array}$ & $\mathbf{n}$ & $\begin{array}{l}\% \text { (in relation to number } \\
\text { treated per target lobe) }\end{array}$ \\
\hline Right upper lobe & 46 & 12 & 7 & 15.2 \\
\hline Right upper lobe/middle lobe & 39 & 10.5 & 2 & 5.1 \\
\hline Middle lobe & 1 & 0.3 & 0 & 0 \\
\hline Right lower lobe & 54 & 14.1 & 8 & 14.8 \\
\hline Right lower lobe/middle lobe & 1 & 0.3 & 0 & 0 \\
\hline Segment 6 right & 1 & 0.3 & 0 & 0 \\
\hline Left upper lobe & 83 & 21.7 & 25 & 30.1 \\
\hline Left lower lobe & 155 & 40.6 & 28 & 18.1 \\
\hline Upper lobes bilateral & I & 0.3 & 0 & 0 \\
\hline
\end{tabular}

RCTs. ${ }^{5,6,13}$ Although valve placement is a minimally invasive therapeutic approach, it is associated with complications of which pneumothorax is the most common. In this analysis, the pneumothorax rate of $18 \%$ was comparable with the rates of $18 \%-25 \%$ reported in other trials..$^{6-8}$ Regarding the management of pneumothorax, $87 \%$ of patients had to undergo chest tube insertion. A comparably high rate of chest drainage of $83 \%$ could also be seen in the recently published STELVIO trial. ${ }^{6}$ The rates of necessary valve explantation of $44 \%$ in the current analysis and 50\% in the STELVIO were also similar.

In $78 \%$ of the patients, the pneumothorax occurred during the first 3 days following valve placement, so that a hospital stay for 48-72 hours for surveillance should be recommended routinely. ${ }^{10}$ In $22 \%$ of the patients, however, pneumothorax occurred after hospital discharge. Therefore, it is of great importance to inform the patients of the symptoms of pneumothorax and explain to them to seek medical help quickly.

Table 3 Clinical outcome of all patients 3 months recovering after pneumothorax

\begin{tabular}{|c|c|c|c|}
\hline \multirow[t]{2}{*}{$\begin{array}{l}\text { Clinical outcome } \\
\text { measures }\end{array}$} & \multicolumn{3}{|c|}{$\begin{array}{l}\text { All patients with pneumothorax } \\
\text { ( } n=70 \text {; baseline- } 3 \text { months following } \\
\text { pneumothorax) }\end{array}$} \\
\hline & $\mathbf{n}$ & Mean \pm SD & $P$-value \\
\hline$\Delta \mathrm{VC}(\mathrm{mL})$ & 53 & $28 \pm 494$ & 0.676 \\
\hline$\Delta \mathrm{VC}$ (\% predicted) & 53 & $1.7 \pm 14.7$ & 0.414 \\
\hline$\Delta \mathrm{FEV}_{1}(\mathrm{~mL})$ & 53 & $55 \pm 148$ & 0.009 \\
\hline$\Delta \mathrm{FEV}_{1}$ (\% predicted) & 53 & $2.0 \pm 5.3$ & 0.007 \\
\hline$\Delta \mathrm{RV}(\mathrm{mL})$ & 50 & $-390 \pm 964$ & 0.006 \\
\hline$\Delta \mathrm{RV}$ (\% predicted) & 50 & $-23.0 \pm 43.3$ & $0.001 *$ \\
\hline$\Delta \mathrm{TLC}(\mathrm{mL})$ & 51 & $-348 \pm 876$ & 0.007 \\
\hline$\Delta \mathrm{TLC}$ (\% predicted) & 51 & $-7.1 \pm 15.8$ & 0.002 \\
\hline$\Delta 6-\mathrm{MWT}(\mathrm{m})$ & 42 & $13.9 \pm 72.9$ & 0.223 \\
\hline$\Delta \mathrm{mMRC}$ (points) & 38 & $-0.2 \pm 1.3$ & 0.400 \\
\hline
\end{tabular}

Note: *Imputation analysis revealed statistical significance.

Abbreviations: SD, standard deviation; VC, vital capacity; $\mathrm{FEV}_{1}$, forced expiratory volume in I second; RV, residual volume; TLC, total lung capacity; 6-MWT, 6-minute walk test; mMRC, modified Medical Research Council.
One retrospective analysis published in 2014 based on the data of 25 patients with pneumothorax following valve implantation revealed that the patients will nevertheless experience a good outcome with a target lobe volume reduction of $65 \% \pm 36 \%$ following valve implantation. ${ }^{4,5,9,14}$ The current analysis of 70 patients with pneumothorax also confirms that a pneumothorax generally has no negative impact on the clinical status. Thereby, mainly patients in whom lobar atelectasis occurred despite pneumothorax will experience a clinically relevant improvement in lung function parameters. The abscence of mean improvement of exercise capacity measured by the 6-MWT, despite the statistically significant improvement in lung function parameters, may result from the prolonged immobilization and the subsequent muscle wasting. ${ }^{15}$ The patients without a significant TLVR - which represents the majority of all

Table 4 Clinical outcome of all patients with pneumothorax but without lobar atelectasis 3 months after recovering from pneumothorax

\begin{tabular}{|c|c|c|c|}
\hline \multirow[t]{2}{*}{$\begin{array}{l}\text { Clinical outcome } \\
\text { measures }\end{array}$} & \multicolumn{3}{|c|}{$\begin{array}{l}\text { All patients with pneumothorax, } \\
\text { but without atelectasis ( } n=48 \text {; } \\
\text { baseline-3 months following } \\
\text { pneumothorax) }\end{array}$} \\
\hline & n & Mean \pm SD & $P$-value \\
\hline$\Delta \mathrm{VC}(\mathrm{mL})$ & 34 & $-5 I \pm 493$ & 0.598 \\
\hline$\Delta \mathrm{VC}$ (\% predicted) & 34 & $-1.1 \pm 14.1$ & 0.449 \\
\hline$\Delta \mathrm{FEV}_{1}(\mathrm{~mL})$ & 34 & $39 \pm 142$ & 0.115 \\
\hline$\Delta \mathrm{FEV},(\%$ predicted $)$ & 34 & $1.3 \pm 4.9$ & 0.119 \\
\hline$\Delta \mathrm{RV}(\mathrm{mL})$ & 32 & $-203 \pm 835$ & 0.179 \\
\hline$\Delta \mathrm{RV}(\%$ predicted) & 32 & $-15.9 \pm 34.0$ & 0.013 \\
\hline$\Delta T L C(m L)$ & 32 & $-237 \pm 805$ & 0.107 \\
\hline$\Delta$ TLC (\% predicted) & 32 & $5.1 \pm 12.8$ & 0.032 \\
\hline$\Delta 6-M W T(m)$ & 26 & $15.4 \pm 75.5$ & 0.308 \\
\hline$\triangle \mathrm{mMRC}$ (points) & 24 & $-0.4 \pm 1.0$ & 0.846 \\
\hline
\end{tabular}

Abbreviations: SD, standard deviation; VC, vital capacity; $\mathrm{FEV}_{1}$, forced expiratory volume in I second; RV, residual volume; TLC, total lung capacity; 6-MWT, 6-minute walk test; mMRC, modified Medical Research Council. 


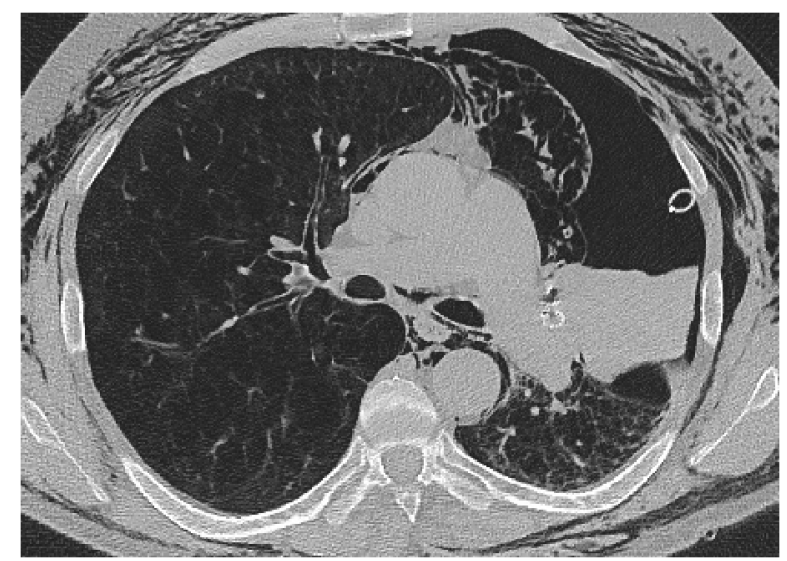

Figure I Multi-detector CT.

Note: Chest tube insertion because of pneumothorax following valve placement in the left upper lobe.

Abbreviation: CT, computed tomography.

pneumothorax patients - experienced only a slight mean improvement in lung function parameters. Overall, $36 \%$ (19/53) and 55\% (23/42) of all pneumothorax patients met the responder criteria for $\mathrm{FEV}_{1}$ and the 6-MWT, respectively. In $11 \%(6 / 53)$ and $29 \%(12 / 42)$ of the patients, a clinically significant worsening of $\mathrm{FEV}_{1}$ and 6-MWT was observed, respectively.

Overall, a great variability in the clinical outcome following valve therapy was observed in the total patient cohort. Another retrospective analysis demonstrated that in patients who develop lobar atelectasis following valve therapy, the changes in lung function parameters, exercise capacity, and dyspnea score depend on different variables, such as the emphysema score of the treated lobe, 6-MWT, VC, and RV at baseline. ${ }^{16}$ It can be assumed that the outcomes following pneumothorax are also influenced by various baseline parameters, resulting in such a great variability.

One explanation for the missing target lobe volume reduction in the majority of patients is the necessity for valve removal because of the pneumothorax. In $44 \%$ of all pneumothorax patients, valve removal was necessary due to persistent collapse of the lung despite chest tube insertion. These patients will not benefit significantly from valve therapy as only a complete occlusion of one lung lobe is associated with a good outcome. ${ }^{17}$ Another explanation may be valve dislocation or dysfunction due to movement of lung parenchyma and bronchi in case of pneumothorax also resulting in a lack of target lobe volume reduction.

Efficacy data showed that pneumothorax is not associated with a clinically relevant improvement in the majority of patients, but it impairs the clinical status only in a minority. Therefore, the relatively high risk of pneumothorax is accepted by most physicians and patients. Nevertheless, the evaluation of pneumothorax predictors to find a balance between efficacy and safety and the evaluation of a prevention strategy of pneumothorax are crucial to minimize this anticipated adverse event of endoscopic lung volume reduction in emphysema patients. In one retrospective analysis, various $\mathrm{CT}$ parameters and clinical variables were found to be significant predictors of pneumothorax. ${ }^{18}$ These
A

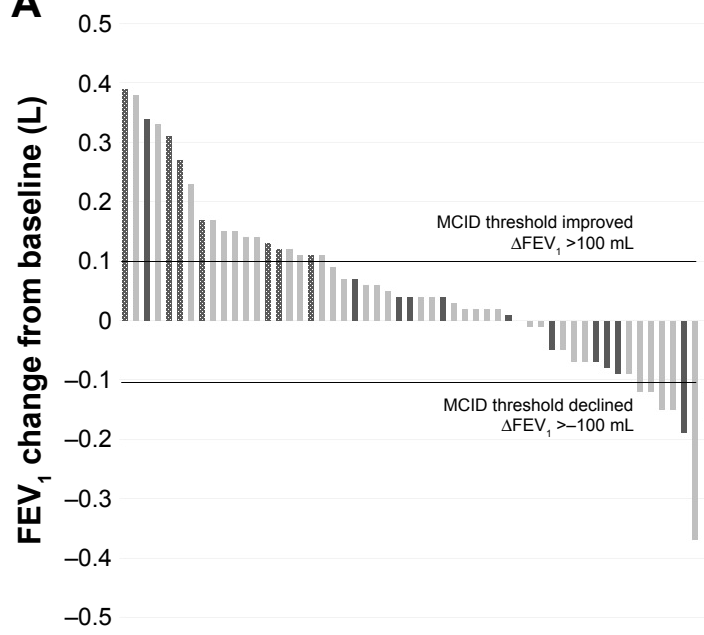

B

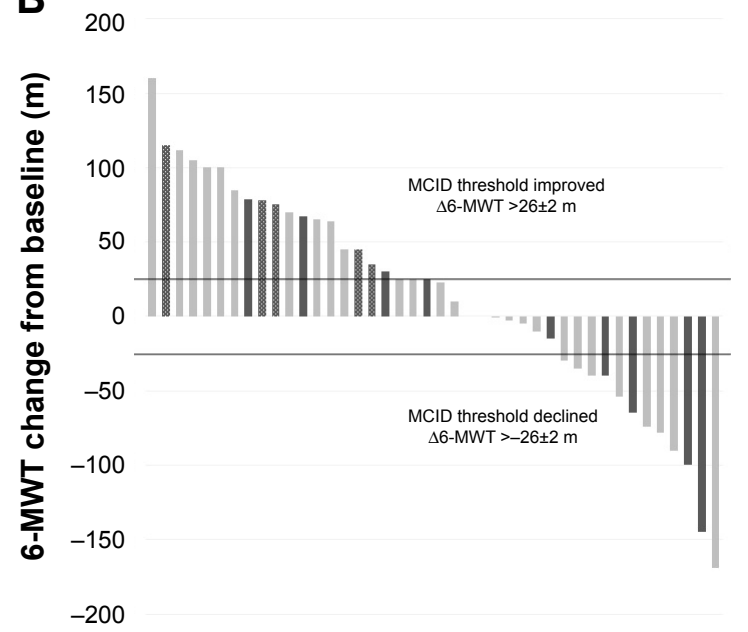

Figure 2 Response rate for FEV, and 6-MWT.

Notes: (A) A bar chart showing the response rate for $\mathrm{FEV}$, change with a bar for each unique individual patient ( $\mathrm{n}=53$ ). Light gray denotes no atelectasis at any time. Dark gray denotes evidence of atelectasis at any time point. Dark gray/dotted represents persistent atelectasis. MCID threshold: improved, FEV $>$ I00 mL; declined, $\mathrm{FEV}_{1}>-100 \mathrm{~mL}$. (B) A bar chart showing response rate for 6-MWT change with a bar for each unique individual patient ( $\mathrm{n=42}$ ). Light gray denotes no atelectasis at any time. Dark gray denotes evidence of atelectasis at any time point. Dark gray/dotted represents persistent atelectasis. MCID threshold: improved, 6-MWT $>26 \pm 2$ m; declined, 6-MWT >-26 $\pm 2 \mathrm{~m}$.

Abbreviations: $\mathrm{FEV}_{1}$, forced expiratory volume in I second; $\mathrm{MCID}$, minimal clinically important difference; 6-MWT, 6-minute walk test. 
Table 5 Clinical outcome 3 months after recovering from pneumothorax of all patients with pneumothorax and lobar atelectasis

\begin{tabular}{|c|c|c|c|}
\hline \multirow[t]{2}{*}{$\begin{array}{l}\text { Clinical outcome } \\
\text { measures }\end{array}$} & \multicolumn{3}{|c|}{$\begin{array}{l}\text { All patients with pneumothorax } \\
\text { and atelectasis (prior/during and } \\
\text { following pneumothorax; } n=28 \text {; } \\
\text { baseline- } 3 \text { months following } \\
\text { pneumothorax) }\end{array}$} \\
\hline & $\mathbf{n}$ & Mean \pm SD & $P$-value \\
\hline$\Delta \mathrm{VC}(\mathrm{mL})$ & 19 & $170 \pm 475$ & 0.136 \\
\hline$\Delta \mathrm{VC}(\%$ predicted $)$ & 18 & $6.9 \pm 14.7$ & 0.062 \\
\hline$\Delta \mathrm{FEV}_{1}(\mathrm{~mL})$ & 19 & $82 \pm 158$ & 0.036 \\
\hline$\Delta \mathrm{FEV}_{1}$ (\% predicted) & 19 & $3.3 \pm 5.8$ & $0.023^{*}$ \\
\hline$\Delta \mathrm{RV}(\mathrm{mL})$ & 18 & $-72 \mid \pm 1.107$ & 0.013 \\
\hline$\Delta \mathrm{RV}(\%$ predicted $)$ & 19 & $-35.1 \pm 54.5$ & 0.012 \\
\hline$\Delta T L C(m L)$ & 18 & $-547 \pm 983$ & 0.030 \\
\hline$\Delta \mathrm{TLC}(\%$ predicted $)$ & 19 & $-10.5 \pm 19.9$ & 0.034 \\
\hline$\Delta 6-M W T(m)$ & 16 & $11.5 \pm 70.9$ & 0.526 \\
\hline$\Delta \mathrm{mMRC}$ (points) & 14 & $-0.4 \pm 1.7$ & 0.374 \\
\hline
\end{tabular}

Note: *Imputation analysis revealed statistical significance.

Abbreviations: SD, standard deviation; VC, vital capacity; FEV, forced expiratory volume in I second; RV, residual volume; TLC, total lung capacity; 6-MWT, 6-minute walk test; mMRC, modified Medical Research Council.

findings, however, will have to be confirmed in a prospective study.

Another retrospective trial evaluating a strategy to prevent pneumothorax found a reduction in risk by maintaining a 48-hour bed rest and the prescription of an antitussive therapy following valve placement. However, the number of treated patients in this analysis was too low to allow a general statement for or against this modified post-interventional strategy. ${ }^{?}$

\section{Conclusion}

In summary, pneumothorax is a frequent complication following endoscopic valve therapy in emphysema patients. Although pneumothorax does not impair the clinical status in the majority of patients during follow-up, this complication needs to be considered a serious adverse event and an emergency in patients with advanced emphysema and limited respiratory reserve. Adequate pneumothorax management, including chest tube insertion, valve removal, or surgical interventions, should be available in any institution performing endoscopic valve therapy. Further research evaluating pneumothorax predictors and prevention strategies are crucial to balance the risk-benefit ratio for patients undergoing endoscopic valve therapy.

\section{Disclosure}

DG has received lecture and travel fees from Pulmonx, Novartis, AstraZeneca, Mundipharma, Berlin-Chemie, and
Grifols. NB has no conflicts of interest. KK has no conflicts of interest. FJFH has received consultant and lecture fees from Astra, Allmirall, Berlin Chemie, Boehringer Ingelheim, Roche, GSK, Pulmonx, PneumRx, Boston Scientific, Medupdate, Grifols, CSL Behring, OmniaMed, Lilly, Novartis, Teva, Uptake, and VitalAire. CPH has stock ownership in medical industry (Stada and GSK). He has patents (Method and Device for Representing the Microstructure of the Lungs, IPC8 Class: AA61B5055FI, PAN: 20080208038, inventors: W Schreiber, U Wolf, AW Scholz, and CP Heussel). He has received consultation or other fees from Schering-Plough (2009 and 2010), Pfizer (2008-2014), Basilea (2008, 2009 and 2010), Boehringer Ingelheim (2010-2014), Novartis (2010 and 2012), Roche (2010), Astellas (2011 and 2012), Gilead (2011-2014), MSD (2011-2013), Lilly (2011), Intermune (2013-2014), and Fresenius (2013 and 2014). He has received no expert testimony. He obtained research funding from Siemens (2012-2014), Pfizer (2012-2014), MeVis (2012 and 2013), and Boehringer Ingelheim (2015). He obtained lecture fees from Gilead (2008-2014), Essex (2008, 2009, and 2010), Schering-Plough (2008, 2009, and 2010), AstraZeneca (2008-2012), Lilly (2008, 2009, and 2012), Roche (2008 and 2009), MSD (2009-2014), Pfizer (20102014), Bracco (2010 and 2011), MEDA Pharma (2011), Intermune (2011-2014), Chiesi (2012), Siemens (2012), Covidien (2012), Pierre Fabre (2012), Boehringer Ingelheim (2012, 2013, and 2014), Grifols (2012), and Novartis (2013, 2014). He has no relationship with the tobacco industry. $\mathrm{HH}$ has no conflicts of interest. RE has received lecture and travel fees from Pulmonx and Olympus. The authors report no other conflicts of interest in this work.

\section{References}

1. Toma TP, Hopkinson NS, Hillier J, et al. Bronchoscopic volume reduction with valve implants in patients with severe emphysema. Lancet. 2003;361(9361):931-933.

2. Snell GI, Holsworth L, Borrill ZL, et al. The potential for bronchoscopic lung volume reduction using bronchial prostheses: a pilot study. Chest. 2003;124(3):1073-1080.

3. Casanova C, Cote C, de Torres JP, et al. Inspiratory-to-total lung capacity ratio predicts mortality in patients with chronic obstructive pulmonary disease. Am J Respir Crit Care Med. 2005;171(6):591-597.

4. Sciurba FC, Ernst A, Herth FJF, et al; VENT Study Research Group. A randomized study of endobronchial valves for advanced emphysema. N Engl J Med. 2010;363(13):1233-1244.

5. Herth FJ, Noppen M, Valipor A, et al; International VENT Study Group. Efficacy predictors of lung volume reduction with Zephyr valves in a European cohort. Eur Respir J. 2012;39(6):1334-1342.

6. Klooster K, ten Hacken NH, Hartman JE, Kerstjens HA, van Rikxoort EM, Slebos DJ. Endobronchial valves for emphysema without interlobar collateral ventilation. $N$ Engl J Med. 2015;373(24):2325-2335.

7. Herzog D, Poellinger A, Doellinger F, et al. Modifying post-operative medical care after EBV implant may reduce pneumothorax incidence. PLoS One. 2015;10(5):e0128097. 
8. Lepper PM, Ballek D, Trudzinski F, et al. Endoscopic lung volume reduction using endobronchial valves in patients with very low FEV1. Am J Respir Crit Care Med. 2014;189:A3052.

9. Gompelmann D, Herth FJF, Slebos DJ, et al. Pneumothorax following endobronchial valve therapy and its impact on clinical outcomes in severe emphysema. Respiration. 2014;87(6):485-491.

10. Valipour A, Slebos DJ, de Oliveira HG, et al. Expert statement: pneumothorax associated with endoscopic valve therapy for emphysemapotential mechanisms, treatment algorithm, and case examples. Respiration. 2014;87(6):513-521.

11. Donohue JF. Minimal clinically important differences in COPD lung function. COPD. 2005;2(1):111-124.

12. Puhan MA, Chandra D, MosenifarZ, et al; National Emphysema Treatment Trial (NETT) Research Group. The minimal important difference of exercise test in severe COPD. Eur Respir J. 2011;37(4):784-790.

13. Davey C, Zoumot Z, Jordan S, et al. Bronchoscopic lung volume reduction with endobronchial valves for patients with heterogeneous emphysema and intact interlobar fissures (the BeLieVeR-HIFI study): a randomised controlled trial. Lancet. 2015;386(9998): 1066-1073.
14. Herth FJ, Eberhardt R, Gompelmann D, et al. Radiological and clinical outcomes of using Chartis ${ }^{\mathrm{TM}}$ to plan endobronchial valve treatment. Eur Respir J. 2013;41(2):302-308.

15. Langen RC, Gosker HR, Remels AH, Schols AM. Triggers and mechanisms of skeletal muscle wasting in chronic obstructive pulmonary disease. Int J Biochem Cell Biol. 2013;45(10):2245-2256.

16. Gompelmann D, Hofbauer T, Gerovasili V, et al. Predictors of clinical outcome in emphysema patients with atelectasis following endoscopic valve therapy: a retrospective study. Respirology. 2016;27(7): 1255-1261.

17. Eberhardt R, Gompelmann D, Schuhmann M, Heussel CP, Herth FJ. Complete unilateral vs partial bilateral endoscopic lung volume reduction in patients with bilateral lung emphysema. Chest. 2012; 142(4):900-908.

18. Gompelmann D, Lim H, Eberhardt R, et al. Predictors of pneumothorax following endoscopic valve therapy in patients with severe emphysema. Int J Chron Obstruct Pulmon Dis. 2016;11:1767-1773.
International Journal of COPD

\section{Publish your work in this journal}

The International Journal of COPD is an international, peer-reviewed journal of therapeutics and pharmacology focusing on concise rapid reporting of clinical studies and reviews in COPD. Special focus is given to the pathophysiological processes underlying the disease, intervention programs, patient focused education, and self management protocols.

\section{Dovepress}

This journal is indexed on PubMed Central, MedLine and CAS. The manuscript management system is completely online and includes a very quick and fair peer-review system, which is all easy to use. Visit http://www.dovepress.com/testimonials.php to read real quotes from published authors.

Submit your manuscript here: http://www.dovepress.com/international-journal-of-chronic-obstructive-pulmonary-disease-journal 